\title{
DESENVOLVIMENTOS CONTÍNUOS DA ACIARIA 1 DA USIMINAS IPATINGA ATRAVÉS DA TECNOLOGIA SLAGLESS $^{\circledR}$ *
}

\author{
Breno Totti Maia ${ }^{1}$ \\ Bruno Orlando de Almeida Santos ${ }^{2}$ \\ Carlos Alberto de Souza ${ }^{3}$ \\ Fabrício Silveira Garajau ${ }^{4}$ \\ Adeilson Roberto Ribeiro ${ }^{5}$ \\ Marcelo de Souza Lima Guerra ${ }^{6}$
}

\section{Resumo}

A aciaria 1 da Usiminas Ipatinga é composta por 03 convertedores BOF e uso de ventaneiras para promover a melhor mistura do banho. No intuito de garantir e melhorar a estabilidade operacional da etapa sopro na produção, foi iniciado uma séria de desenvolvimentos na lança de oxigênio através da aplicação da tecnologia Slagless ${ }^{\circledR}$ com objetivos de melhorar a formação de escória, evitar cascão de lança, evitar cascão no sistema OG (recuperação de gases) e aumentar a disponibilidade de lanças através do aumento de sua vida. Os resultados apresentados são extremamente favoráveis, pois após a implementação da tecnologia, todos os objetivos foram atingidos associado com uma vida extremamente elevada do bico de lança, agora chamado cartucho, garantindo estabilidade e conforto operacional para a equipe da aciaria 1 da Usiminas Ipatinga.

Palavras-chave: BOF; Sopro; Cartucho; Vida de bico; Cascão.

\section{CONTINUOUS DEVELOPMENTS AT THE STEELPLANT 1 USIMINAS IPATINGA THROUGH SLAGLESS ${ }^{\circledR}$ TECHNOLOGY}

\section{Abstract}

The steelplant 1 Usiminas Ipatinga consists of 03 BOF converters and use of tuyeres to promote better mixing of the bath. This is the challenge of steelmaking operation continues associated with extremes controls operating costs. Thus, blowing stage is critical to ensure steel volumes planned. In order to ensure and improve the operational stability of the blowing stage in the production, started a series of developments in the oxygen lance through the Slagless ${ }^{\circledR}$ technology application by targets: to improve slag formation, avoid lance skulls, avoid skulls at OG system (gas recovery) and increase lance availability by increasing your life. The results are extremely favorable. After the implementation of the technology, all objectives were achieved associated with extremely high lance tip life, now called cartridge, ensuring operational stability and comfort for the staff of one for steelplant 1 Usiminas Ipatinga.

Keywords: BOF; Blow; Cartridge; Tip life; Skull.

1 Engenheiro Metalurgista e Doutor Pesquisador da Lumar Metals, Sócio da ABM, Belo Horizonte, MG, Brasil.

2 Engenheiro de Materiais e Pesquisador da Lumar Metals, sócio da ABM, Ipatinga, MG, Brasil. (In memoriam).

Engenheiro Metalurgista da USIMINAS, sócio da ABM, Ipatinga, MG, Brasil.

Engenheiro Mecânico e Pesquisador da Lumar Metals, sócio da ABM, Ipatinga, MG, Brasil.

Técnico Metalurgista e Assistente Técnico da Usiminas, sócio da ABM, Ipatinga, MG, Brasil.

Engenheiro Mecânico e Pesquisador da Lumar Metals, sócio da ABM, Ipatinga, MG, Brasil. 


\section{INTRODUÇÃO}

O BOF (Basic Oxygen Furnace) é um importante reator na produção do aço, sendo atualmente responsável por $53 \%$ do volume mundial produzido. A Usiminas situada na cidade de Ipatinga possui duas aciarias, ambas operando com convertedores BOF, sendo a Aciaria 1 composta por 03 convertedores com capacidade de 80 toneladas de aço vazado e a Aciaria 2 com 02 convertedores com capacidade de 175 toneladas de aço vazado. Os convertedores são vasos metálicos revestidos com tijolos refratários e sustentados por uma cinta metálica que permite seu basculamento em alguns casos de $360^{\circ}$ graus possibilitando operações importantes na sequencia de produção como o carregamento de gusa e sucata e o vazamento de aço e escória em seus distintos momentos. A Figura 1 apresenta o desenho esquemático de um BOF [1].

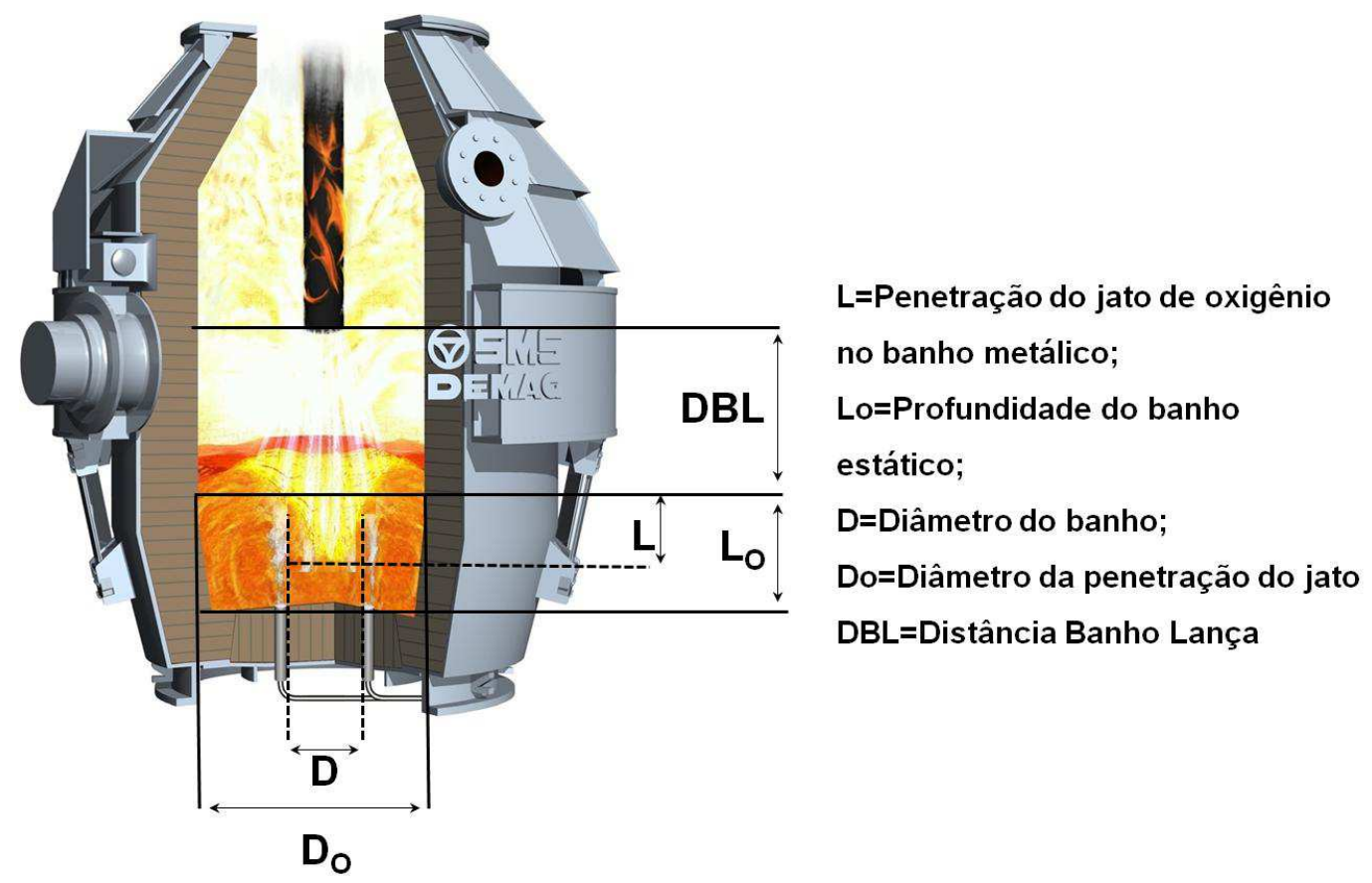

Figura 1 - Desenho esquemático de um convertedor de aço BOF.

Pelo topo uma lança metálica e movimentada para o interior do forno e em determinada altura é injetado oxigênio para iniciar as operações de refino. $\mathrm{Na}$ extremidade da lança, no estado da técnica atual predominante, encontra-se uma peça de cobre chamada de bico de lança, cabeça ou ponta cuja função é distribuir o oxigênio pelas passagens denominadas de lavais, furos ou bocais que variam de furo único a multifuros em até 6 saídas. As condições de processo podem levar ao efeito indesejável chamado de "projeção", que causa a adesão do banho metálico mais escória no corpo lança, laterais superiores do forno chamada cone e em caso extremo ao fechamento do sistema de captação de gases. A tecnololgia Slagless é um novo conceito para o conjunto lança e bico de lança que vem sendo desenvolvido desde 2006, introduzindo o conceito de cartucho, que consiste no aumento da parte refrigerada em cobre do bico tradicional associado a uma geometria peculiar permitindo ajustes operacionais com a redução drástica da adesão de materiais. Atrelado a essa tecnologia, são introduzidos no bocal ajustes particulares as condições de cada convertedor promovendo a estabilidade do sopro. 


\section{MATERIAIS E MÉTODOS}

A metodologia utilizada tomou como base a estrutura do relato de anomalias ou Método de Solução de Problemas (MSP) que consiste nas seguintes etapas: Observação, Análise, Proposta de Ações, Execução e Verificação dos Resultados.

\section{1 - Observação}

Dentro da rotina operacional são frequentes as adesões de escória e metal no corpo da lança e em situações específicas e extremas podendo atingir o sistema de recuperação e lavagem de gás provocando restrição na passagem dos gases podendo inclusive obstruir calhas e bocais. Desta forma, forçando paradas não programadas para manutenção e limpeza dos dutos. O bico de lança era composto de 03 bocais de saída principiais e um furo central com o propósito de refrigerar a face do bico conforme apresentado na Figura 2.

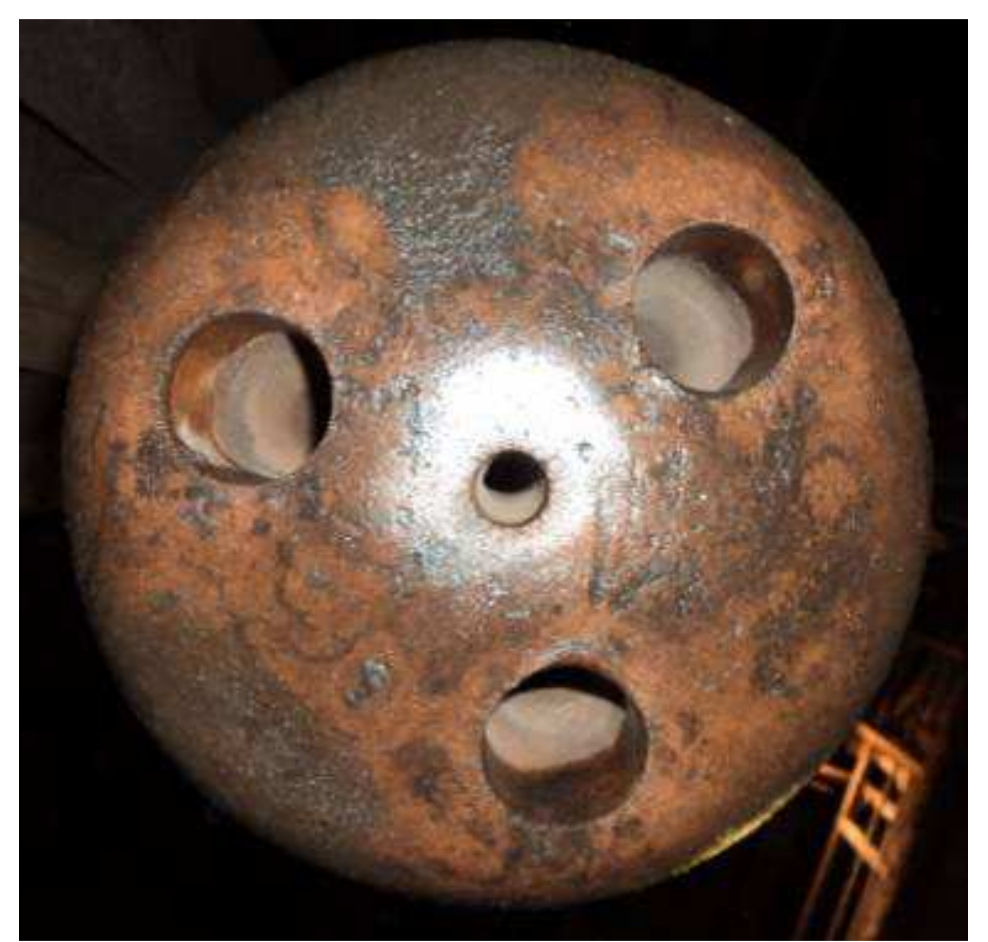

Figura 2 - Desenho do bico de 03 bocais de saída principais e furo central.

\section{2 - Análise}

$\mathrm{Na}$ análise das causas foi utilizada a visualização geométrica para investigar a configuração de bico atual e outras possibilidades conforme apresentado na Figura 3. 


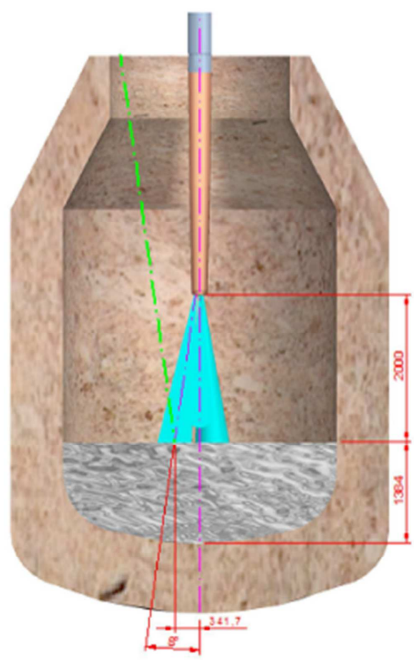

a)

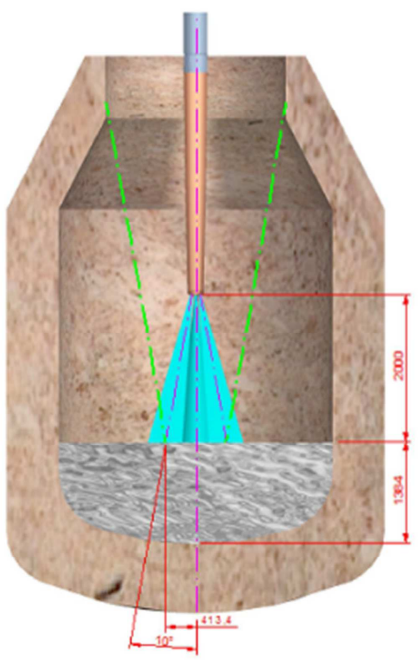

b)

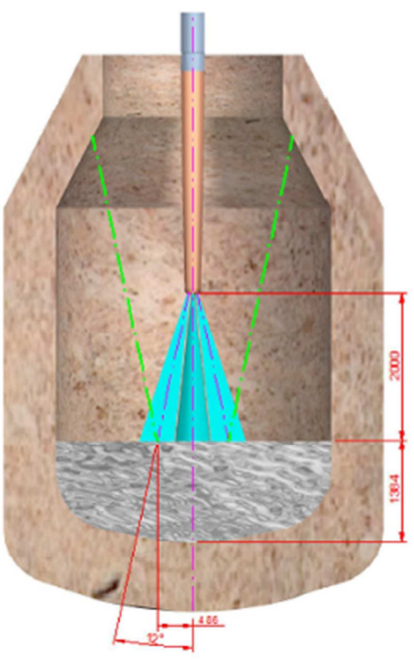

c)

Figura 3 - Comparação geométrica do ângulo de saída do bico e reflexão para: a) $8^{\circ}$ b) $10^{\circ}$ e c) $12^{\circ}$.

Na Figura 3 é possível notar que o ângulo atual de 8o projeta uma linha de reflexão que direciona eventuais projeções de material metálico e escória direto para o sistema de recuperação e lavagem de gás. Para o novo projeto o ângulo entre furos deveria ser alterado com intuito de direcionar as linhas de projeção para o interior do convertedor, mesmo que implicasse em uma maior incidência de cascão de boca, porém com técnicas existentes para melhor conter esse fenômeno indesejável, conforme apresentado na Tabela 1.

Tabela 1 - Comparativo do efeito do jato sobre as condições de sopro.

\begin{tabular}{|c|c|c|c|}
\hline Tipo de Bico & Hood & Boca & Ventaneira \\
\hline 3 Bocais $8^{\circ}$ & $\begin{array}{l}\text { Possibilidade do material } \\
\text { incandescente atingir o } \\
\text { sistema em caso de } \\
\text { projeções. }\end{array}$ & Sem interferência & Sem interferência \\
\hline 4 Bocais $10^{\circ}$ & Sem interferência & $\begin{array}{l}\text { Possível aumento de } \\
\text { necessidade de limpeza de } \\
\text { boca e de fossa devido } \\
\text { derrames pela carcaça. }\end{array}$ & Sem interferência \\
\hline 4 Bocais $12^{\circ}$ & Sem interferência & $\begin{array}{c}\text { Possível formação de cascão } \\
\text { interno. Necessidade de } \\
\text { Slagless Clean Up (Pós - } \\
\text { Combustão) }\end{array}$ & Sem interferência \\
\hline 6 Bocais $17,5^{\circ}$ & Sem interferência & $\begin{array}{c}\text { Possível formação de cascão } \\
\text { interno. Necessidade de } \\
\text { Slagless Clean Up (Pós - } \\
\text { Combustão) }\end{array}$ & $\begin{array}{c}\text { Possibilidade de } \\
\text { interferência } \\
\text { Abaixamento de DBL, } \\
\text { avaliar influência do } \\
\text { desgaste dos } \\
\text { munhões. }\end{array}$ \\
\hline
\end{tabular}

Para o cálculo dos valores teóricos de penetração no banho foram correlacionados a quantidade de movimento do jato através de um balanço de energia na base da cavidade, correlacionado com o número modificado de Froude, conforme a adequação das equações desenvolvidas por Szekely [2], Meidani et al [3] e Alam et al [4-6], proposta por Maia [7]: 


$$
\frac{\pi \times \rho_{g} \times V_{s}^{2} \times d^{2} \times \cos \theta \times n}{4 \times \rho_{l} \times g \times H^{3}}=\frac{2}{K^{2}} \frac{P}{H}\left(1+\frac{P}{H \times \cos \theta}\right)^{2}
$$

Onde " $\rho_{\mathrm{g}}$ " - densidade na saída do bocal $\left(\mathrm{kg} \cdot \mathrm{m}^{-3}\right)$, " $\mathrm{V}_{s}$ " - velocidade na saída do

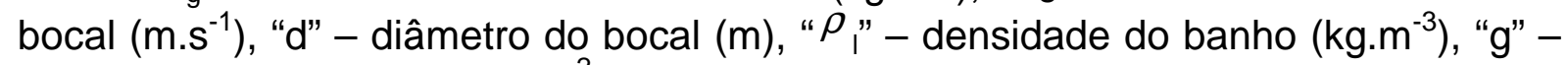
aceleração da gravidade $\left(m \cdot s^{-2}\right)$, "P" - Penetração $(m)$, "H" - Distância da lança ao banhou ou DBL $(m)$, "K" - uma constante empírica para cada tipo de bico, " $\theta$ " ângulo de cada um dos furos dos bicos com a vertical, "n" - número de furos do bico. A partir da equação (1) foi possível estimar o comportamento do jato sobre o banho metálico considerando parâmetros de pressão e vazão característicos da aciaria 1, conforme apresentado na Figura 4.

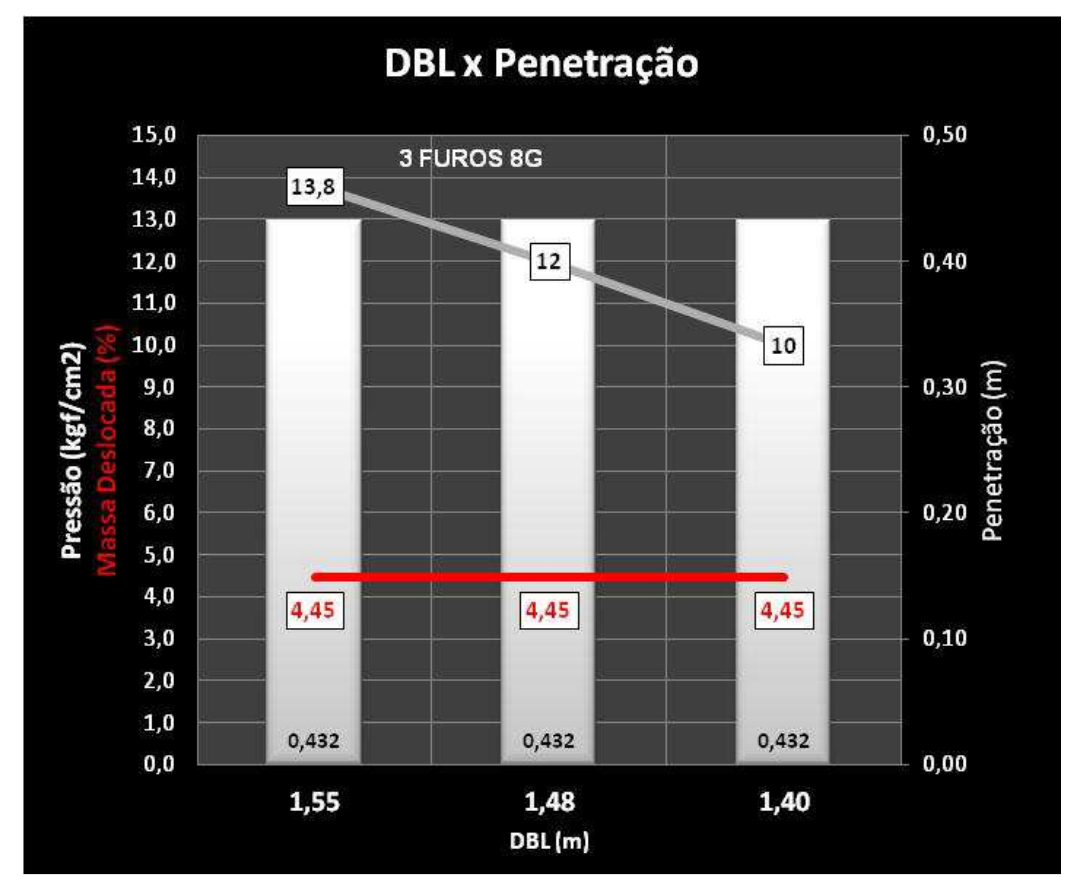

Figura 4 - Balanço de energia para as condições do bico de 03 furos da aciaria 1.

Na Figura 4 é possível perceber que para uma mesma penetração de jato e uma altura de lança segura para evitar danos no bico de lança a pressão do bico tem que ser aumentada e a quantidade de massa movimentada é pequena em todos os casos $4,45 \%$.

Adicionalmente o furo central, apesar de refrigerar o bico, provoca uma oxidação excessiva da emulsão e consequente descontrole do sopro. Na tentantiva de evitar as projeções para fora do convertedor e mesmo no sistema de recuperação e lavagem de gás os operadores contam com dois recursos: reduzir a altura de lança ou reduzir a vazão de sopro. Em ambos os casos, as condições não são favoráveis para o bico de cobre, sendo no primeiro pelo aumento da carga térmica e no segundo caso pelo efeito do jato sobrexpandido pela redução da vazão gerando desgastes prematuros nas saídas dos Lavais conforme Figura 5. 


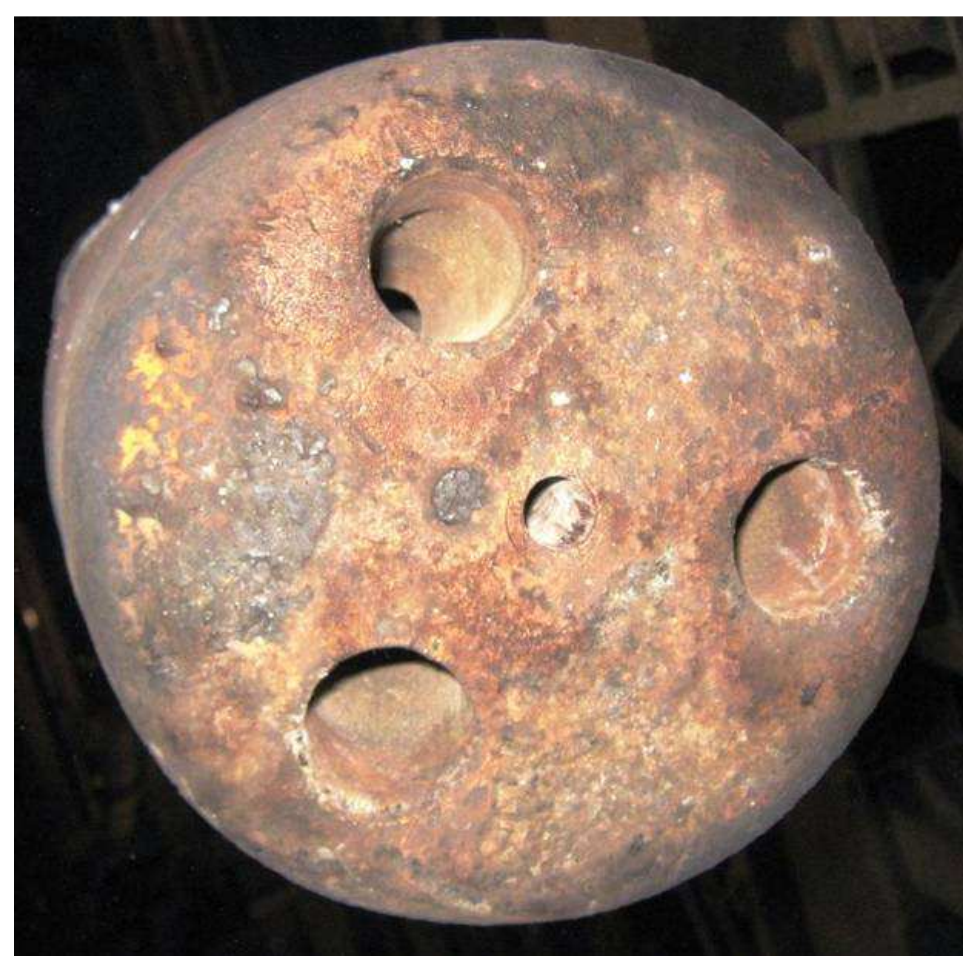

Figura 5 - Bico de 03 furos com desgaste de Laval por jato sobrexpandido.

\section{3 - Proposta de Ações}

Para nortear a proposta de ações foram estabelecidas metas a serem alcançadas, as quais:

- Reduzir a formação de cascão na lança;

- Eliminar a formação de cascão no sistema de recuperação e lavagem de gás;

- Aumentar a vida da lança;

- Aumentar a estabilidade de sopro;

Para atingir as metas estabelecidas a atenção foi centrada na lança de oxigênio, sendo inserida a tecnologia Slagless para o alcance dos objetivos.

A tecnologia Slagless consiste em um conjunto de alterações no corpo da lança com o objetivo de maximizar a troca térmica e facilitar a remoção de eventuais partículas metálicas ou escórias aderidas. Para tanto a lança é alterada sendo inserido um cartucho de cobre de aproximadamente 03 metros em substituição ao bico tradicional, conforme imagem da Figura 6. 


\section{$46^{\circ}$}
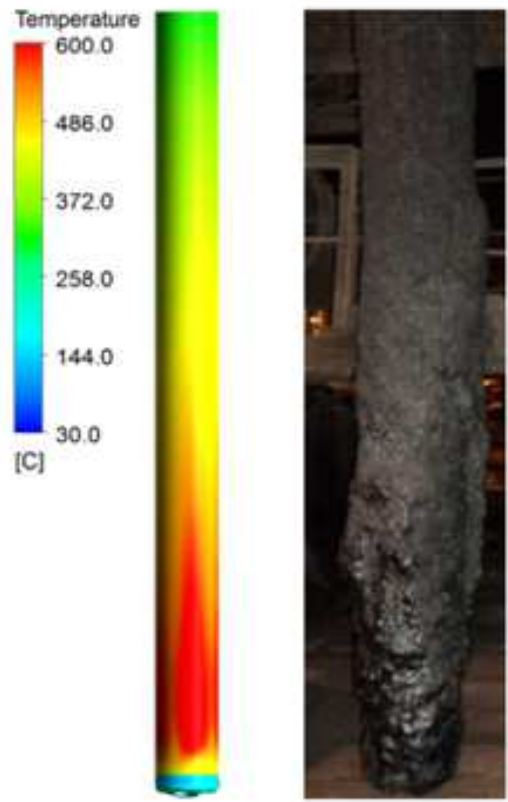

a)

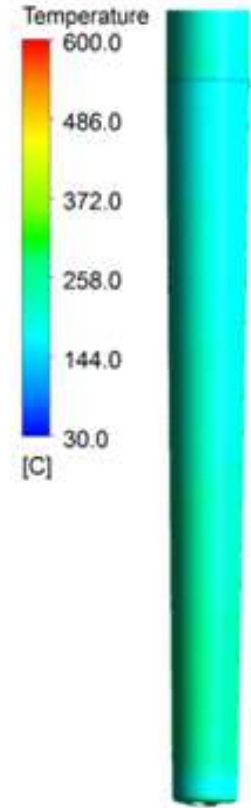

b)

Figura 6 - Comparativo de adesão de projeção e capacidade de extração térmica: a) Bico convencional e b) cartucho Slagless.

Na Figura 6 é possível notar que além do acréscimo no corpo de cobre. Somado a esse fato, internamente, em função da vazão e pressão de água disponíveis é projetado um complexo circuito de refrigeração cujo objetivo é maximizar a velocidade da água e seu contato com a parede do tubo de cobre, maximizando a troca térmica, provocando forte contração em qualquer material que por ventura venha a aderir, facilitando sua queda.

Para melhorar as condições de formação de escória e massa movimentada para o mesmo valor de penetração, porém a pressões mais baixas, o bico foi alterado de 03 para 04 furos, conforme Figura 7.

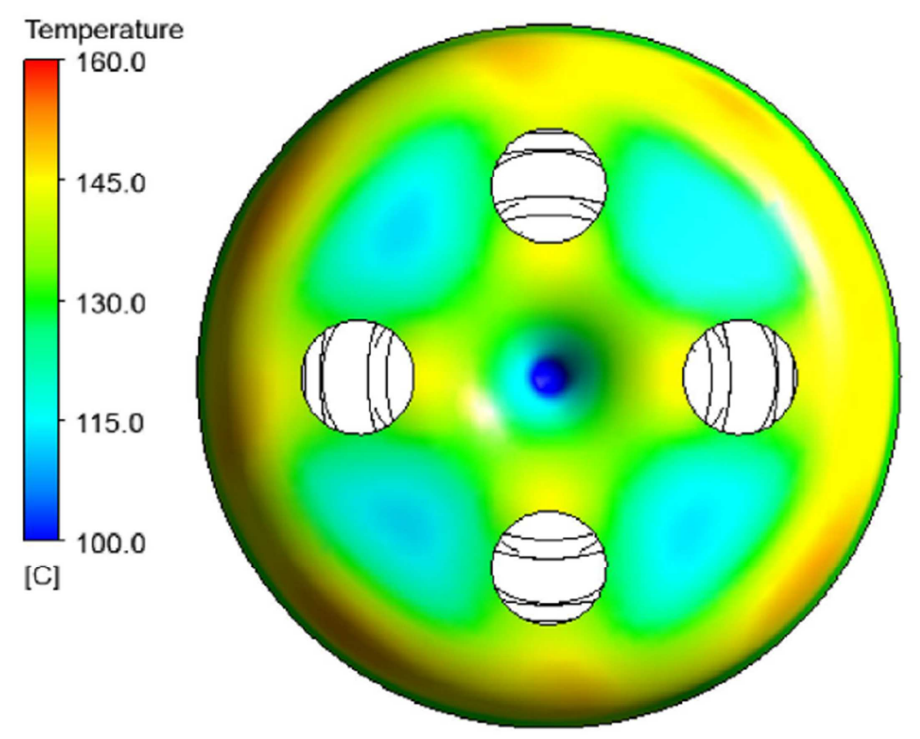

Figura 7 - Novo bico projetado para $14.000 \mathrm{Nm}^{3} / \mathrm{h} @ 10 \mathrm{kgf} / \mathrm{cm}^{2} \mathrm{com}$ ângulo de 10․ 
O desenho da Figura 7 foi projetado para trabalhar com pressão inferior à pressão normal de trabalho. Essa ação teve objetivo de contemplar a necessidade dos operadores de reduzir vazão durante os eventos de projeção de material particulado com o efeito benéfico de preservar a integridade do bocal através de um jato sempre uniforme mesmo em baixas vazões.

O ângulo entre furos com a vertical foi aumentado e através da inspeção das linhas geométricas apresentadas na Figura 3 é possível verificar que potencialmente deve ocorrer uma menor incidência de acúmulo de material no sistema de captação de gases.

Após a concepção do novo bico de 04 furos foi realizado novo balanço de momento conforme apresentado na Figura 8.

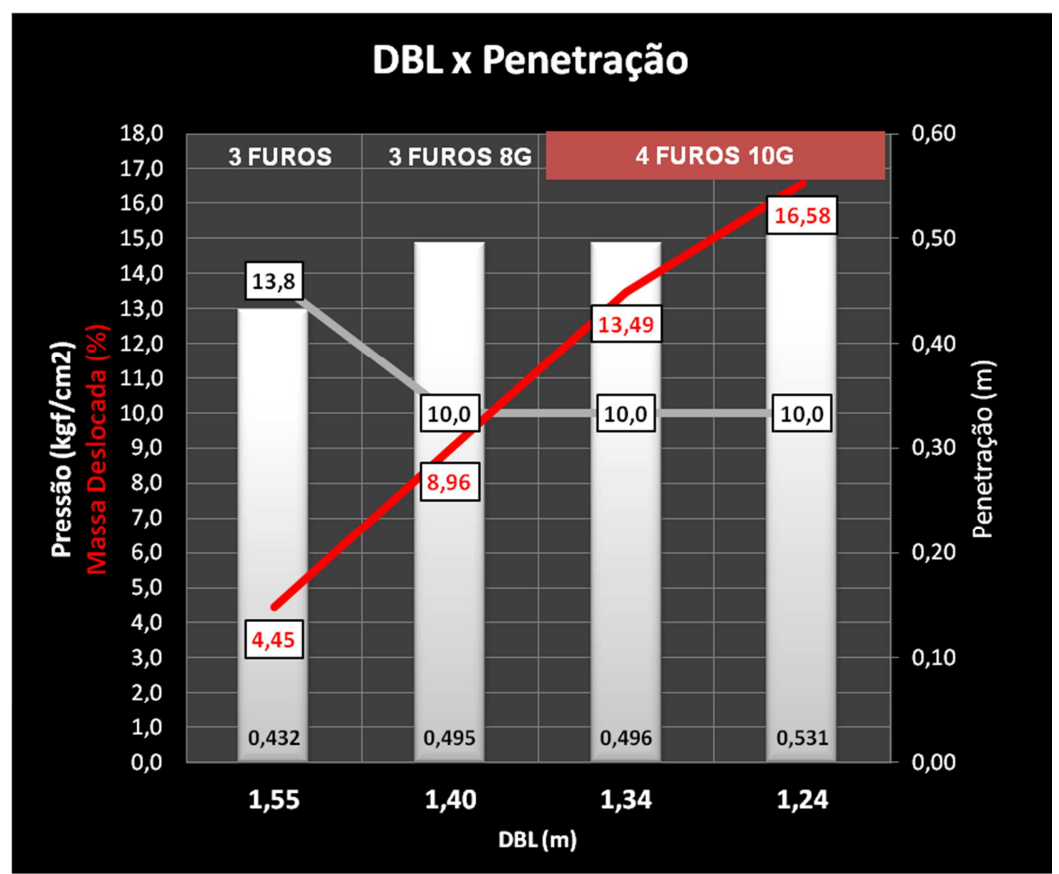

Figura 8 - Balanço de energia para as condições do bico de 04 furos da aciaria 1.

Na Figura 8 o parâmetro de calibração entre o bico de 03 furos e o bico de 04 furos foi a penetração, no caso, a referência penetração do bico de 03 furos a $10 \mathrm{~kg} / \mathrm{cm}^{2}$. Essa condição foi transferida para o bico 04 furos, provocando descida de lança ou redução do DBL (Distância Banho Lança) inferior a 100mm. No entanto é possível verificar um aumento aproximado de $4 \%$ na massa movimentada. Uma redução de mais $100 \mathrm{~mm}$ na condição leva a massa movimentada para próximo de $17 \%$, ou seja, em torno de 4 vezes a massa movimentada para bico de 03 furos com maior pressão e DBL.

\section{RESULTADOS E DISCUSSÃO}

\section{1 - Vida do Cartucho}

Após as implementações efetuadas um aumento na vida média dos cartuchos conforme apresentado na Tabela 2. 
Tabela 2 - Vida Média e Máxima dos Cartuchos

\begin{tabular}{|c|c|c|c|c|c|c|c|}
\hline \multicolumn{4}{|l|}{ Média de Vida } & \multicolumn{4}{|c|}{ Máx de Vida } \\
\hline Ano & $\nabla$ Mês & 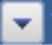 & Total & Ano $\quad \nabla \nabla$ & Mês & $\nabla$ & Total \\
\hline-2013 & & 1 & 45 & -2013 & & 1 & 45 \\
\hline & & 6 & 354 & & & 6 & 354 \\
\hline & & 7 & 165 & & & 7 & 165 \\
\hline & & 8 & 132 & & & 8 & 341 \\
\hline & & 9 & 31 & & & 9 & 68 \\
\hline & & 10 & 95 & & & 10 & 95 \\
\hline & & 11 & 364 & & & 11 & 658 \\
\hline & & 12 & 685 & & & 12 & 685 \\
\hline 2013 Total & & & 246 & 2013 Total & & & 685 \\
\hline-2014 & & 1 & 695 & $=2014$ & & 1 & 777 \\
\hline & & 3 & 385 & & & 3 & 606 \\
\hline & & 4 & 448 & & & 4 & 891 \\
\hline & & & 313 & & & 5 & 313 \\
\hline & & 6 & 1175 & & & 6 & 1175 \\
\hline & & 8 & 1428 & & & 8 & 1428 \\
\hline 2014 Total & & & 579 & 2014 Total & & & 1428 \\
\hline Total geral & & & 417 & Total geral & & & 1428 \\
\hline
\end{tabular}

Na Tabela 2 é possível notar que no período de 2014 (04 bocais) o valor médio da vida de cartucho está em 579 corridas em média, 2 vezes a vida média no ano de 2013 (03 bocais). Outro fato é que ao longo do período foram feitos ajustes na altura de lança permitindo um desempenho crescente na vida dos cartuchos chegando ao máximo de 1428 corridas em agosto de 2014. Na Tabela 2 estão contabilizados todos os afastamentos de lança, incluindo causas operacionais, mecânicas e elétricas dentro da operação dos convertedores. Considerando apenas afastamentos ligados a vida de cartucho a média de vida dos cartuchos é de 856 corridas. A Figura 9 apresenta um gráfico comparativo.

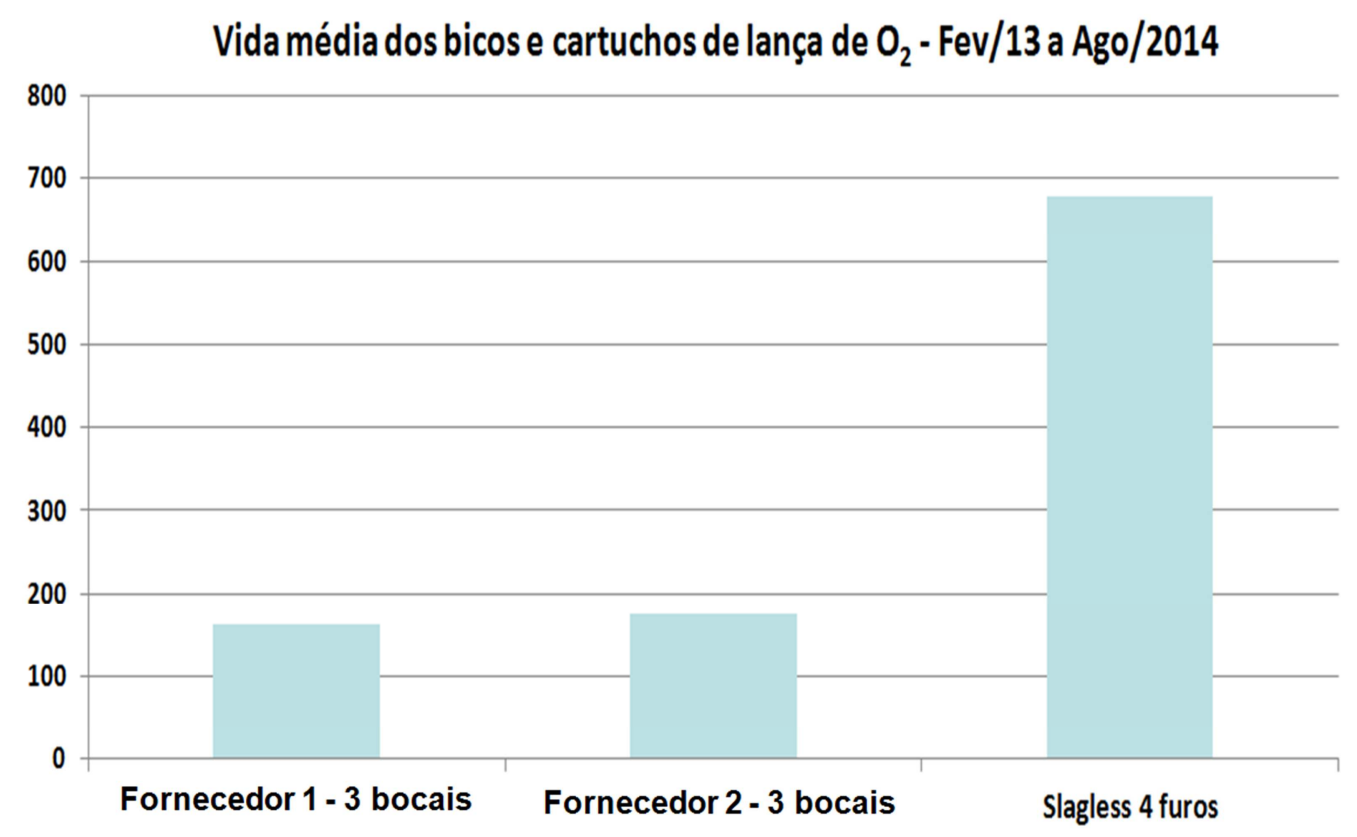

Figura 9 - Comparativo de desempenho do cartucho Slagless 04 furos. 


\section{2 - Ocorrências de Cascão de Lança}

No mesmo período a ocorrência do cascão foi comparada com bico convencional conforme apresentado na Tabela 3.

Tabela 3 - Comparativo de formação de cascão de lança.

\begin{tabular}{ccc}
\hline Tipo de Lança & Bico Convencional & $\begin{array}{c}\text { Cartucho } \\
\text { Slagless }\end{array}$ \\
\hline Corridas até parada por cascão & $\mathbf{1 9}$ & $\mathbf{5 2 1}$ \\
Incidência de cascão (lanças/mês) & 63 & 2,3 \\
Efetivo manutenção turno & 6 mecânicos (02 por horário) & 0 \\
Efetivo manutenção no administrativo & 02 mecânicos & 1 \\
\hline
\end{tabular}

Com a efetiva troca térmica no corpo da lança implementada com a tecnologia Slagless as condições dos tubos de cobre e aço foram mantidas evitando retiradas para manutenção e possíveis danos causados durante a remoção de metal ou escória aderida e retirada por meio de oxicorte.

\section{3 - Ocorrências de Cascão no Sistema de Recuperação e Lavagem de Gás}

A Tabela 4 apresenta um histórico de 02 anos sobre a ocorrências de formação de cascões no sistema de recuperação e lavagem de gás da Usiminas Aciaria 1 denominado OG.

Tabela 4 - Histórico de formação cascão no sistema OG entre 2011 e 2012

\begin{tabular}{cccc}
\hline Convertedor & Data & $\begin{array}{c}\text { Tempo de Parada } \\
\text { (dias) }\end{array}$ & Motivo \\
\hline 1 & Fevereiro / 2011 & 5 & Cascão entre o capuz móvel e fixo \\
3 & Agosto / 2011 & 10 & $\begin{array}{c}\text { Cascão entre o capuz móvel e fixo + } \\
\text { troca de capuz }\end{array}$ \\
1 & Outubro / 2011 & 8 & Cascão entre o capuz móvel e fixo \\
1 & Fevereiro / 2012 & 8 & $\begin{array}{c}\text { Cascão na saia móvel, operando } \\
\text { sem água e necessidade de troca }\end{array}$ \\
\hline
\end{tabular}

Conforme previsto com o aumento do ângulo entre furos não foi observado nenhuma ocorrência de fechamento do sistema de captação de gases posterior as ações implementadas.

\section{4 - Condições dos Bocais}

A condição dos bocais mantém preservada devido ao projeto eficiente de refrigeração associado com os parâmetros considerados no dimensionamento dos bocais conforme apresentado na Figura 10. 


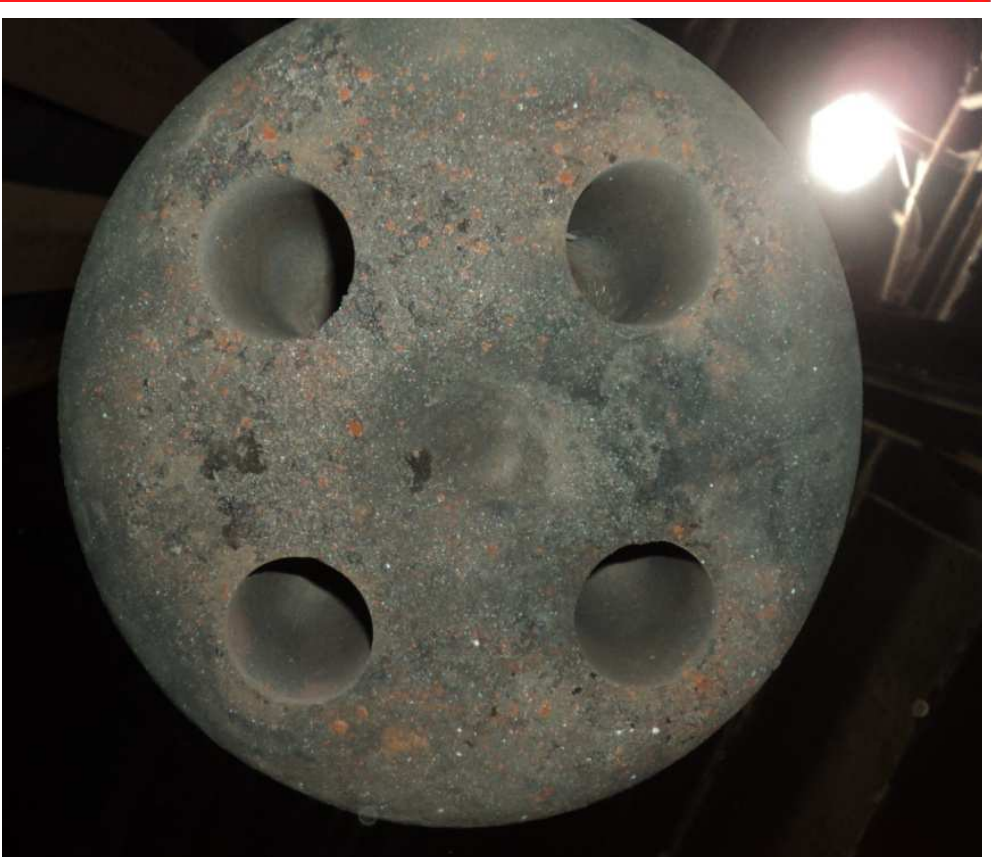

Figura 10 - Foto da face do bico de 04 furos da Aciaria 1 da Usiminas com 247 corridas.

$\mathrm{Na}$ Figura 10, nota-se que não existe desgaste entre os bocais, sinalizando que a troca térmica tem sido efetiva. Nos bocais é comum observar desgaste nas saídas principalmente na região próxima ao centro do bico provocado principalmente pelas reduções de vazões para contenção de projeções. Novamente, através da Figura 10, o correto dimensionamento considerando as flutuações de vazão dentre das etapas de sopro foram suficientes para manter a boa integridade dimensional da saída dos bocais.

\section{CONCLUSÃO}

Descrição das principais conclusões:

1. A atualização do Cartucho Slagless reduziu a formação de cascão na lança em 35 vezes quando comparada com a lança convencional;

2. A mudança da geometria do bico contribuiu significativamente para melhoria das condições de trabalho e segurança dos colaboradores envolvidos em manobras e trocas de lança de oxigênio e peças do $O G$, devido a redução drástica de formação de cascões;

3. O Cartucho Slagless permitiu o direcionamento da equipe de manutenção para outras atividades como preditivas e preventivas;

4. Os desenvolvimentos contínuos de 3 para 4 furos elevaram a vida do Cartucho Slagless em 02 vezes comparando 2013 com 2014;

5. A vida do Cartucho Slagless é 3,5 vezes superior ao bico convencional. Vida útil elevada e metalurgia de sopro estável sem projeção garantiram estabilidade a Aciaria 1 tornando-a mais segura e competitiva.

\section{Agradecimentos}

Os autores agradecem ao Lumar Metals e a Usiminas ao incentivo a pesquisa e desenvolvimentos. Ao Bruno Orlando de Almeida Santos, amigo eterno! 


\section{REFERÊNCIAS}

1 ODENTHAL, H. J., EMLING, W. H., KEMPKEN, J., SCHLUTER, J. Advantageous Numerical Simulation of the Converter Blowing Process. AISTECH 2007.

2 SZEKELY, J. THEMELIS, N. J., Rate Phenomena in Process Metallurgy. 1 ed. Montreal: John Wiley \& Sons, 1971. 784p.

3 MEIDANI, A. R. N., ISAC, M., RICHARDSON, A., CAMERON, A., GUTHRIE, R. I. L. Modeling Shrouded Supersonic Jets in Metallurgical Reactor Vessels. ISIJ International, 2004, v.44, n.10, p. 1639-1645.

4 ALAM, M., IRONS, G., BROOKS, G., FONTANA, A., NASER, J., Inclined Jetting and Splashing in Electric Arc Furnace Steelmaking. ISIJ International, 2011, v.51, n.9, p. 1439-1447.

5 ALAM, M., NASER, J., BROOKS, G., FONTANA, A. Computational Fluid Dynamics Modeling of Supersonic Coherent Jets for Electric Arc Furnace Steelmaking Process. Metallurgical and Materials Transactions B, volume 41B, p.1354-1367. Dec. 2010.

6 ALAM, M., NASER, J., BROOKS, G., FONTANA, A. Computational Fluid Dynamics Simulation of Supersonic Oxygen Jet Behavior at Steelmaking Temperature Metallurgical and Materials Transactions B, volume 41B, p.636-645. Jun. 2010.

7 MAIA, B. T., Modelamento Físico e Matemático do Escoamento de Fluidos nos processos BOF e EOF. Belo Horizonte: Escola de Engenharia da UFMG, 2013. 238p. (Tese, Doutorado em Engenharia Metalúrgica). 